Research Article

\title{
Site Selection of Solar Farms Deploying Fuzzy Analytical Hierarchy Process (F-AHP) A KPK Based Study
}

\author{
Rehman Akhtar ${ }^{1}$, Khizar Azam ${ }^{2}$, Abdur Rehman Babar ${ }^{1}$, Qazi Salman Khalid ${ }^{1}$, Rashid Nawaz ${ }^{1}$ and Imran \\ Ahmad $^{1}$
}

${ }^{1}$ Department of Industrial Engineering, University of Engineering and Technology, Peshawar, Pakistan; ${ }^{1}$ Department of Mechanical Engineering, University of Engineering and Technology, Peshawar, Pakistan.

Abstract: Solar energy that is produced through solar farms is a freely available, renewable source of energy
that reduces greenhouse effect. It holds utmost importance in a developing country with power shortcomings
and pollution issues. Choosing the best site for a solar farm amid various location alternatives is a complex
multiple criteria decision making (MCDM) problem as numerous conflicting qualitative and quantitative
criteria demands to be considered. Based on the literature review the factors selected for the study are Quality
of Terrain, Land price, Population, Security, Proximity to Transmission Line, Agricultural Concern and
Local Transmission Capacity. One of the most frequently used MCDM methods in literature, the Analytical
Hierarchy Process (AHP) is integrated with fuzzy logic, called as F-AHP, is used in this research to identify
and evaluate solar farm location in division of Khyber Pakhtunkhwa (KPK). Thana, Chakdara, Harichand,
Palai, Pir Khel and Shergarh city are evaluation by Fuzzy AHP on the basis of above-mentioned factors.
Shergarh city is selected for most suitable location for the installation of solar panels.
Received: January 13, 2020; Accepted: May 23, 2020; Published: June 19,2020
"Correspondence: Qazi Salman Khalid, Department of Industrial Engineering. University of Engineering and Technology, Peshawar, Khyber
Pakhtunkhwa, Pakistan; Email: qazisalman@uetpeshawar.edu.pk
Citation: Akhtar, R., K. Azam, A.R. Babar, Q.S. Khalid, R. Nawaz and I. Ahmad. 2020. Site selection of solar farms deploying fuzzy analytical
hierarchy process (F-AHP) A KPK based study. Journal of Engineering and Applied Sciences, 39(1): 14-21.
DOI: http://dx.doi.org/10.17582/journal.jeas/39.1.14.21
Keywords: Solar farm location selection, Fuzzy logic, Multiple-criteria decision making, AHP

\section{Introduction}

$\mathrm{E}$ lectricity is a vital inf rastructure for socioeconomic development of a country. Majority of energy around the globe is processed form fossil fuels which has a great impact on world's economy, ecology and climate. Prices of fossil fuel and oil have observed unprecedented increase in recent decade; so, most of the countries have considered new policies for reducing energy cost and depleting pollution. Renewable energy enlightens aforementioned aspects, and solar energy is one of the efficient among them. In a developing country like Pakistan, especially in Khyber Pakhtunkhwa (KP) belt area, where industrial zones are been established through China-Pakistan June 2020 | Volume 39 | Issue 1 | Page 14
Economic Corridor, the demand for electricity is increasing continuously. So, there is a potential of establishing solar power generation stations more than ever. Currently, various authors studied problems of solar power plants (SPP) and basically comprises of following different areas: Thermal storage systems (Antipova et al., 2013; Flueckiger et al., 2014; Flueckiger and Garimella, 2014; Guillot et al., 2012; Muñoz et al., 2012; Rovira et al., 2011; Yang and Garimella 2013), cooling systems (Deng and Boehm, 2011; Iverson et al., 2013; Dominguez et al., 2012), planning and design of SPP (Peng et al., 2014; Sanz-Bermejo et al., 2014), assessment and comparison between present SPP projects (AvilaMarin et al., 2014; Azofra et al., 2014; Desideri and 
Cpmpana, 2014; Jafarian et al., 2014; Peng et al., 2014; Wu et al., 2010). On site selection problem of $\mathrm{SPP}$, limited research study is available, such as Xio et al. (2013), applied analytical hierarchy process (AHP) and geographic information system (GIS) in order to search site selection model for desert photo-voltaic power plants and Uyan (2013) utilized GIS and AHP to identify best sites for solar farms.

Site selection is critical factor for efficiency of solar farm; various government and Non-Government Organizations (NGO) are in a puzzle state to come with valuable solutions. On the contrary, if site selection comes out to be poor, billions of initial investments and cultivates from the land could be at stake leading towards a disaster at socio-economic upfront. Moving forward, since the selection of SPP site has a firm relation with its security and ought to meet the meteorological prerequisite, society and environment necessity, and financial aspects (Yunna et al., 2013). Determination of suitable site relies on arrangement of criteria and its surroundings; like, proper sunlight oriented areas, barometrical conditions which changes accessibility of sunlight. Further, environmental conditions play vital role and it not does only lessen the quantity of insolation achieved by earth's surface but also influences the quality of insolation by retention and dispersion of light with fluctuated ranges. Another concern is the interest of some social and financial criteria, in the assessment of the landscape; one such criterion is vicinity of the selected site to power transmission lines, changing over stations, and populated neighborhood (Arran-Carrion et al., 2007). Similarly, Van-Haaren and Fthenakis (2011) also conducted a study on various challenges like, monetary and environmental aspects for SPP site selection. It is well understood that site selection determines future electric energy production and socio-economic values of the power stations; these deserve to be paid extra attention. From the above-mentioned references, it is known that site selection is multi criteria decision making (MCDM) problem.

Amongst different MCDM techniques that may be applied on evaluation of land for site selections phenomenon, AHP strategy (Saaty, 2008) stands out. It integrates the expert opinion and assessment scores to a simpler hierarchical system through decomposition of complex problems from higher to lower levels. Likewise, Analytic Network Process
(ANP) is a multi-attribute approach too, which transforms the qualitative to quantitative values. AHP is considered as a unique case of ANP that does not have feedback loop amongst the factors; ANP is considered effective by most researchers for long term selection of projects. However, in MCDM, recent studies are been carried out by incorporating uncertainty and ambiguousness of experts in which opinion is a noticeable trait of the problem, and this impreciseness of human judgment is tackled with set of fuzzy, developed by Zadeh (1965). Fuzzy AHP (F-AHP) technique (Cheng, 1997; Cheng et al., 1999), and Ruoning and Xiaoyan (1992) methodically solves the selection problems, utilizing the concepts of hierarchical structure analysis combined with fuzzy set theory. Fundamentally, F-AHP technique enhances standard AHP into fuzzy domain with the use of fuzzy numbers, instead of calculating real numbers Petkovic et al. (2012).

Furthermore, ANP operates with only with crisp relationship ratios, while on other hand, human judgments comprising of uncertainty can be operated with Fuzzy ANP; having weights calculation simpler than traditional ANP Önüt et al. (2009). In literature, many applications of F-AHP are present in variety of selection fields, with high recommendation. These include: Personnel selection Güngör (2009), alternatives of energy selection Dağdeviren and Yuksel (2009), selection of weapon Kahraman and Kaya (2010), jobs selection Kilic and Cevikcan (2011). Wu et al., (2014) has carried out a study on selection of site for thermal power plant based on fuzzy measure of linguistic Choquet operator. Recently, Aktas and Kabak (2019), applied a hybrid hesitant fuzzy decision-making approach to determine locations for solar power plants. However, to the best of knowledge, there is no study found with SPP site selection based on F-AHP in developing regions like Pakistan. Fuzzy AHP details are given in next section.

\section{Materials and Methods}

\section{Fuzzy analytical hierarchy process}

F-AHP embeds fuzzy theory in to standard AHP. It is commonly used as a decisive tool in multi criterion environment problems. It operates by selecting pairwise comparison of various alternatives to different criteria, providing a decision support tool. In standard AHP model, the first level is objective of the study, second level is criteria and third one is sub criteria and 
alternatives are set to be on the fourth level Kilincci and Onal (2011). Major concern with standard AHP is that of not considering vagueness for personal judgments, and F-AHP covers this gap. In F-AHP, linguistic variables are used to perform pair-wise comparisons of both; alternatives and criteria, been represented by triangular numbers Van Laarhoven et al. (1983). Various authors contributed through their work on F-AHP including (Chang, 1996; Chou and Chang, 2008). In current work, Buckley's technique (1985) is applied to consider the relative weightage importance for criteria and alternatives. The procedure is as follows:

Step 1: In this step decision maker matches the criteria through linguistic terms as shown in below Figure 1 .

\begin{tabular}{|c|c|c|}
\hline Saaty scale & Definition & Fuzzy Triangular Scale \\
\hline 1 & Equally important (Eq. Imp.) & $(1,1,1)$ \\
\hline 3 & Weakly important (W. Imp.) & $(2,3,4)$ \\
\hline 5 & Fairly important (F. Imp.) & $(4,5,6)$ \\
\hline 7 & Strongly important (S. Imp.) & $(6,7,8)$ \\
\hline 9 & Absolutely important (A. Imp.) & $(9,9,9)$ \\
\hline 2 & \multirow{4}{*}{$\begin{array}{c}\text { The intermittent values between two } \\
\text { adjacent scales }\end{array}$} & $(1,2,3)$ \\
\hline 4 & & $(3,4,5)$ \\
\hline 6 & & $(5,6,7)$ \\
\hline 8 & & $(7,8,9)$ \\
\hline
\end{tabular}

Figure 1: Linguistic terms along with corresponding triangular fuzzy numbers.

Conferring to the triangular fuzzy numbers of linguistic relations from Table 1 , suppose that decision maker sets Criterion $\mathrm{C} 1$ strong in importance to $\mathrm{C} 2$, fuzzy triangular scale as $(6,7,8)$ will be selected. In contrast, the pair wise contribution matrix for criteria, comparison of $\mathrm{C} 2$ with $\mathrm{C} 1$ will select fuzzy scale like $(1 / 8,1 / 7,1 / 6)$.

The pair wise contribution matrix is presented in Equation 1, where $\tilde{e}_{i j}{ }_{i j}$ indicates the preference of the $\mathrm{k}^{\text {th }}$ decision maker for the $\mathrm{i}^{\text {th }}$ criterion over the $\mathrm{j}^{\text {th }}$, by means of fuzzy triangular numbers. At this point, "tilde" displays the triangular number demo, for example, $\mathrm{e}_{12}^{1}$ depicts the preference of first decision maker for the first criterion over the second, such as; $\mathrm{e}_{12}^{1}=(2,3,4)$

$$
\widetilde{L^{k}}=\begin{array}{ccc}
\widetilde{e_{11}^{k}} & \widetilde{e_{12}^{k}} & \ldots \widetilde{e_{1 n}^{k}} \\
\widetilde{e_{n 1}^{k}} & \widetilde{e_{n 2}^{k}} & \ldots \widetilde{e_{n n}^{k}}
\end{array}
$$

Step 2: If there multi decision makers, each decision maker's preference $\left(\mathrm{e}_{\mathrm{ij}}^{\mathrm{k}}\right)$ are averaged and $\tilde{\mathrm{e}_{\mathrm{ij}}}$ is calculated as by Equation 2 .

$$
\widetilde{e_{l \jmath}}=\frac{\sum_{k=1}^{K} \widetilde{e_{l j}}}{K}
$$

Step 3: Rendering to averaged preferences from Equation 2, the pair wise contribution matrix is updated as depicted from Equation 3.

$$
\widetilde{L}=\begin{array}{ccc}
\widetilde{e_{11}} & \ldots & \widetilde{e_{1 n}} \\
\tilde{e_{n 1}} & \cdots & \vdots \\
\tilde{e_{n n}}
\end{array}
$$

Step 4: Referring to Buckley (1985), the fuzzy comparison's geometric mean values of each criterioncalculated as illustrated in Equation 4. Here, ${ }^{\sim}$ still denotes triangular values.

$$
\widetilde{p_{l}}=\left(\prod_{j=1}^{n} \widetilde{e_{l j}}\right)^{1 / n}, i=1,2, \ldots, n
$$

Step 5: The fuzzy weights of each criterion are calculated with Equation 5, by following next 3 sub steps.

Step 5-1: Calculate the summation of vectors for each $\tilde{p}_{i}$. Step 5-2: Determine (-1) power of summation vector. Afterwards, substitute the fuzzy triangular number, to put it in incremental order.

Step 5-3: To calculate the fuzzy weight of the $\mathrm{i}^{\text {th }}$ criterion $\tilde{x_{i}}$, multiply each $\tilde{p_{i}}$ with this reverse vector.

$$
\widetilde{x_{l}}=\widetilde{p_{l}} \otimes\left(\widetilde{p_{1}} \oplus \widetilde{p_{2}} \bigoplus \quad \ldots \oplus \widetilde{p_{n}}\right)^{-1}=\left(l x_{i}, m x_{i}, u x_{i}\right) \ldots
$$

Step 6: Since $\tilde{x_{i}}$ are fuzzy triangular numbers, these require de-fuzzification by center of area technique proposed by Chou and Chang (2008), as shown in Equation 6.

$$
Y_{i}=\frac{\left(l x_{i}, m x_{i}, u x_{i}\right)}{3}
$$

Step 7: $\mathrm{Y}_{\mathrm{i}}$ is a non-fuzzy numeric. Though, it requires to be normalized with the Equation 7 .

$$
Z_{i}=\frac{Y_{i}}{\sum_{i=1}^{n} Y_{i}}
$$

The aforementioned seven steps are performed to determine the normalized weightages of the criteria and alternatives subsequently. Afterwards, each alternative weight is multiplied with it relevant criteria and the scores of each alternative is evaluated. Alternative with largest score is proposed to the decision maker. In our SSP site selection, this methodology is applied and its results are discussed in the coming section. 


\section{Factor selection}

The selection of the factors for analyzing the solar panel's location selection process solely based on literature review and expert opinion. Al Garni et al. (2018), Lee et al. (2017), Noorollahi (2016), identified various factors for selecting a solar panel location. The factors selected on the basis of previous research are given as: QT: Quality of Terrain; LP: Land Price; S: Security; W: Population; LTC: Local Transmission Capacity; PTL: Proximity to Transmission Line; AC: Agricultural Concern.

These factors are analyzed with Fuzzy AHP and the best city according to these factors is selected. The cities which are considered are Thana, Chakdara, Harichand, Palai, Pir Khel, Shergarh.

Few other factors like annual average daylight hours, annual average air temperature, annual average clearances index are also considered for these locations. Literature shows that the ideals values for like annual average daylight hours, annual average air temperature and annual average insolation clearances index should be maximum or equal to 12 hours, $25 \mathrm{C}$ and 0.55 respectively. The annual average humidity level should be between 44-52 Chakraborty et al. (2014). The meteorological data for the selected locations are obtained from National Aeronautics and Space Administration (NASA) surface meteorology and solar energy (SSE) database. The obtained data shows that all the factors have the ideal values for the selected locations and are suitable for installation of solar panels.

\section{Calculating the weight of the criteria}

In the $1^{\text {st }}$ step, for selecting the weight of the criteria, a questionnaire was designed and distributed to the industry expert and researchers (which carried out the research on solar panels). Total 70 questionnaires were distributed among which 50 questionnaires were sent to the industry experts and 20 to the researchers. The total questionnaires received were 52, 38 from the industry experts and 14 from the researchers. On the basis of the questionnaire the average of the response is shown in Table 1.

In $2^{\text {nd }}$ and $3^{\text {rd }}$ step, the pairwise comparison matrix for the criteria is created from the questionnaire response as depicted in Table 2.

After making the pairwise matrix, now in step 4, relative humidity and annual average insolation

the geometric mean of the weights is calculated. For simplicity, the calculation of only one value is shown here, that is for 1st criteria QT, the Quality of Tarain; $=\left[\left(1^{*} 1 / 4^{*} 1 / 6^{*} 1 / 9^{*} 1 / 6^{*} 1 / 6^{*} 1 / 8^{*} 1 / 8\right)^{1 / 8} ;\left(1^{*} 1 / 3^{*} 1 / 5^{*} 1 / 9^{*}\right.\right.$ $\left.1 / 5^{*} 1 / 5^{*} 1 / 7^{*} 1 / 7\right)^{1 / 8} ;\left(1^{*} 1 / 2 * 1 / 4^{*} 1 / 9^{*} 1 / 4^{*} 1 / 4^{*} 1 / 6^{*} 1 / 6\right)^{1}$ $\left.{ }^{/ 8}\right]=(0.194 ; 0.223 ; 0.265)$

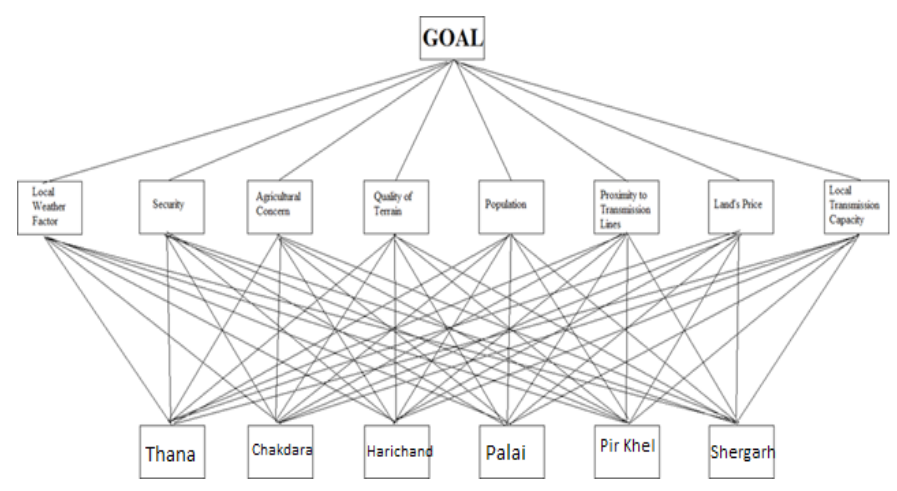

Figure 2: Factors are alternatives for AHP analysis.

Table 1: Pairwise criteria on the basis of questionnaire.

\begin{tabular}{|c|c|c|c|c|c|c|c|c|}
\hline $\begin{array}{l}\text { Cri- A. } \\
\text { teria Imp }\end{array}$ & $\begin{array}{ll}\text { S. } & \text { F. } \\
\text { Imp } & \text { Imp }\end{array}$ & $\begin{array}{l}\text { W. } \\
\text { Imp }\end{array}$ & $\begin{array}{l}\text { Crite- E. } \\
\text { rion Imp }\end{array}$ & $\begin{array}{l}\text { Cri- } \\
\text { terion }\end{array}$ & $\begin{array}{l}\text { A. } \\
\text { Imp }\end{array}$ & $\begin{array}{l}\text { S. } \\
\text { Imp }\end{array}$ & & $\begin{array}{l}\text { W. } \\
\text { p Imp }\end{array}$ \\
\hline 1 & & & QT & LP & & & & 1 \\
\hline 2 & & & QT & S & & & 1 & \\
\hline 3 & & & QT & W & 1 & & & \\
\hline 4 & & & $\mathrm{QT}$ & LTC & & & 1 & \\
\hline 5 & & & QT & PTL & & & 1 & \\
\hline 6 & & & QT & $\mathrm{AC}$ & & 1 & & \\
\hline 7 & & & QT & $\mathrm{P}$ & & 1 & & \\
\hline 8 & & & LP & S & & & & 1 \\
\hline 9 & & & LP & W & & & 1 & \\
\hline 10 & & & LP & LTC & & & 1 & \\
\hline 11 & & & LP & PTL & & & 1 & \\
\hline 12 & & & LP & $\mathrm{AC}$ & & 1 & & \\
\hline 13 & & & LP & $\mathrm{P}$ & & 1 & & \\
\hline 14 & & & S & W & & & 1 & \\
\hline 15 & & & S & LTC & & & & 1 \\
\hline 16 & & & S & PTL & & & 1 & \\
\hline 17 & & & S & $\mathrm{AC}$ & & & 1 & \\
\hline 18 & & & S & $\mathrm{P}$ & & 1 & & \\
\hline 19 & 1 & & W & LTC & & & & \\
\hline 20 & 1 & & $\mathrm{~W}$ & PTL & & & & \\
\hline 21 & & 1 & W & $\mathrm{AC}$ & & & & \\
\hline 22 & & 1 & W & $\mathrm{P}$ & & & & \\
\hline 23 & & & LTC & PTL & & & & 1 \\
\hline 24 & & & LTC & $\mathrm{AC}$ & & & 1 & \\
\hline 25 & & & LTC & $\mathrm{P}$ & & & 1 & \\
\hline 26 & & & PTL & $\mathrm{AC}$ & & & & 1 \\
\hline 27 & & & PTL & $\mathrm{P}$ & & & & 1 \\
\hline 28 & & & $\mathrm{AC}$ & $\mathrm{P}$ & & & & 1 \\
\hline
\end{tabular}
June 2020 | Volume 39 | Issue 1 | Page 17 
Table 2: Pair wise matrix of all the criteria.

\begin{tabular}{lllllllll}
\hline Criteria & QT & LP & S & W & LTC & PTL & AC & P \\
\hline QT & $(1,1,1)$ & $(1 / 4,1 / 3,1 / 2)$ & $(1 / 6,1 / 5,1 / 4)$ & $(1 / 9,1 / 9,1 / 9)$ & $(1 / 6,1 / 5,1 / 4)$ & $(1 / 6,1 / 5,1 / 4)$ & $(1 / 8,1 / 7,1 / 6)$ & $(1 / 8,1 / 7,1 / 6)$ \\
LP & $(2,3,4)$ & $(1,1,1)$ & $(1 / 4,1 / 3,1 / 2)$ & $(1 / 6,1 / 5,1 / 4)$ & $(1 / 6,1 / 5,1 / 4)$ & $(1 / 6,1 / 5,1 / 4)$ & $(1 / 8,1 / 7,1 / 6)$ & $(1 / 8,1 / 7,1 / 6)$ \\
S & $(4,5,6)$ & $(2,3,4)$ & $(1,1,1)$ & $(1 / 6,1 / 5,1 / 4)$ & $(1 / 4,1 / 3,1 / 2)$ & $(1 / 6,1 / 5,1 / 4)$ & $(1 / 6,1 / 5,1 / 4)$ & $(1 / 8,1 / 7,1 / 6)$ \\
W & $(9,9,9)$ & $(4,5,6)$ & $(4,5,6)$ & $(1,1,1)$ & $(6,7,8)$ & $(4,5,6)$ & $(2,3,4)$ & $(2,3,4)$ \\
LTC & $(4,5,6)$ & $(4,5,6)$ & $(2,3,4)$ & $(1 / 8,1 / 7,1 / 6)$ & $(1,1,1)$ & $(1 / 4,1 / 3,1 / 2)$ & $(1 / 6,1 / 5,1 / 4)$ & $(1 / 6,1 / 5,1 / 4)$ \\
PTL & $(4,5,6)$ & $(4,5,6)$ & $(4,5,6)$ & $(1 / 6,1 / 5,1 / 4)$ & $(2,3,4)$ & $(1,1,1)$ & $(1 / 4,1 / 3,1 / 2)$ & $(1 / 4,1 / 3,1 / 2)$ \\
AC & $(6,7,8)$ & $(6,7,8)$ & $(4,5,6)$ & $(1 / 4,1 / 3,1 / 2)$ & $(4,5,6)$ & $(2,3,4)$ & $(1,1,1)$ & $(1 / 4,1 / 3,1 / 2)$ \\
P & $(6,7,8)$ & $(6,7,8)$ & $(6,7,8)$ & $(1 / 4,1 / 3,1 / 2)$ & $(4,5,6)$ & $(2,3,4)$ & $(2,3,4)$ & $(1,1,1)$ \\
\hline
\end{tabular}

The above value shows the geometric mean for the first criteria. The geometric mean for the rest of the criteria can be calculated in the same manner. The value for geometric mean for all the criteria is shown in Table 3.

Table 3: Geometric mean for all the criteria.

\begin{tabular}{llll}
\hline Criteria & \multicolumn{3}{l}{ Geometric mean } \\
\hline Quality of terrain & 0.194 & 0.223 & 0.265 \\
Land price & 0.278 & 0.336 & 0.414 \\
Security & 0.429 & 0.524 & 0.648 \\
Weather & 3.293 & 4.039 & 4.726 \\
Local transmission capacity & 0.639 & 0.784 & 1.147 \\
Proximity to transmission line & 1.037 & 1.303 & 1.646 \\
Agricultural concern & 1.707 & 2.120 & 2.632 \\
Population & 2.328 & 2.910 & 3.538 \\
Sum & 9.906 & 12.241 & 15.018 \\
Reverse (Power of -1) & 0.101 & 0.081 & 0.066 \\
Ascending order & 0.066 & 0.081 & 0.101 \\
\hline
\end{tabular}

Table 4: Relative fuzzy weightage for each criterion.

\begin{tabular}{llll}
\hline Criteria & \multicolumn{3}{l}{ Weightage } \\
\hline Quality of terrain & 0.0129 & 0.0182 & 0.0267 \\
Land price & 0.0185 & 0.0275 & 0.0418 \\
Security & 0.0286 & 0.0428 & 0.0655 \\
Weather & 0.2193 & 0.3300 & 0.4771 \\
Local transmission capacity & 0.0425 & 0.0641 & 0.1158 \\
Proximity to transmission line & 0.0690 & 0.1065 & 0.1662 \\
Agricultural concern & 0.1136 & 0.1732 & 0.2657 \\
Population & 0.1550 & 0.2378 & 0.3572 \\
\hline
\end{tabular}

After calculating the geometric mean, the values are added and their reverse is calculated. Then the reverse value is arranged in ascending order. The Fuzzy weightage of the first criteria, QT over the rest of criteria can be calculated as:

$\left[(0.194 * 0.066) ; \quad(0.223 * 0.081) ; \quad\left(0.265^{*} 0.101\right)\right]=$
$[0.0129,0.0181,0.0267]$

The relative fuzzy weightage for the other criterion is presented in Table 4.

For each criterion, three fuzzy values are shown in the table. The fuzziness in the system can be removed by following the step six, which is, by taking the average of each fuzzy value. This will give a single non fuzzy weight. Also, the weights are normalized in Table 5.

Table 5: Non-fuzzy and normalized weights for all criteria.

\begin{tabular}{lll}
\hline Criteria & $\begin{array}{l}\text { Non-fuzzy } \\
\text { weight } \mathbf{M}_{\mathbf{i}}\end{array}$ & $\begin{array}{l}\text { Normalized } \\
\text { weight } \mathbf{~}_{\mathbf{i}}\end{array}$ \\
\hline Quality of terrain & 0.0193 & 0.0182 \\
Land price & 0.0293 & 0.0277 \\
Security & 0.0456 & 0.0431 \\
Weather & 0.3421 & 0.3232 \\
Local transmission capacity & 0.0741 & 0.0700 \\
Proximity to transmission line & 0.1139 & 0.1076 \\
Agricultural concern & 0.1842 & 0.1740 \\
Population & 0.2500 & 0.2362 \\
\hline $\begin{array}{l}\text { The normalized weight shows the importance of each criterion with } \\
\text { respect to each other. }\end{array}$
\end{tabular}

In the next step, the weight of alternatives is determined w.r.t each criterion. The same seven steps are followed to determine the weight of each alternative and it is shown in Table 6.

Now the weight of each criterion is multiplied with the weights, the result is as follow, depicted in Table 7. It also shows that when calculated all the values of alternative along with their respective weights, Shergarh is the best option to install the solar panels. The $2^{\text {nd }}$ best option available to install the solar panels is Thana and Palai. 
Table 6: Weightage of each criterion with respect to the alternatives.

\begin{tabular}{|c|c|c|c|c|c|c|}
\hline Criteria & $\begin{array}{l}\text { Tha- } \\
\text { na }\end{array}$ & $\begin{array}{l}\text { Chak- } \\
\text { dara }\end{array}$ & $\begin{array}{l}\text { - Hari- } \\
\text { chand }\end{array}$ & Palai & $\begin{array}{l}\text { Pir } \\
\text { Khel }\end{array}$ & $\begin{array}{l}\text { Sher- } \\
\text { garh }\end{array}$ \\
\hline Quality of terrain & 0.026 & 0.053 & 0.090 & 0.157 & 70.242 & 0.433 \\
\hline Land price & 0.359 & 0.050 & 0.027 & 0.109 & 0.17 & 0.277 \\
\hline Security & 0.026 & 0.053 & 0.090 & 0.157 & 70.242 & 0.433 \\
\hline Weather & 0.275 & 0.079 & 0.169 & 0.405 & 0.028 & 0.045 \\
\hline $\begin{array}{l}\text { Local transmission } \\
\text { capacity }\end{array}$ & 0.284 & 40.388 & 0.028 & 0.168 & 0.047 & 0.085 \\
\hline $\begin{array}{l}\text { Proximity to trans- } \\
\text { mission line }\end{array}$ & -0.268 & 0.101 & 0.407 & 0.149 & 0. & 0.027 \\
\hline Agricultural concer & rn 0.189 & 9.101 & 0.029 & 0.053 & 0.369 & 0.260 \\
\hline Population & 0.176 & 60.092 & 0.038 & 0.389 & 0.055 & 0.250 \\
\hline & & & & & & \\
\hline Criteria & Thana & $\begin{array}{l}\text { Chak- I } \\
\text { dara h }\end{array}$ & $\begin{array}{l}\text { Haric- } \\
\text { hand }\end{array}$ & Palai & $\begin{array}{l}\text { Pir } \\
\text { Khel }\end{array}$ & $\begin{array}{l}\text { Sher- } \\
\text { garh }\end{array}$ \\
\hline Quality of terrain & $0.000 \quad 0$ & $0.001 \quad 0$ & 0.002 & 0.003 & 0.004 & 0.008 \\
\hline Land price & $0.007 \quad 0$ & 0.0010 & 0.000 & 0.002 & 0.003 & 0.005 \\
\hline Security & $0.000 \quad 0$ & 0.0010 & 0.002 & 0.003 & 0.004 & 0.008 \\
\hline Weather & $0.005 \quad 0$ & 0.0010 & 0.003 & 0.007 & 0.001 & 0.001 \\
\hline $\begin{array}{l}\text { Local transmis- } \\
\text { sion capacity }\end{array}$ & $0.005 \quad 0$ & $0.007 \quad 0$ & 0.001 & 0.003 & 0.001 & 0.002 \\
\hline $\begin{array}{l}\text { Proximity to } \\
\text { transmission line }\end{array}$ & 0.005 & 0.002 & 0.007 & 0.003 & 0.001 & 0.000 \\
\hline $\begin{array}{l}\text { Agricultural } \\
\text { concern }\end{array}$ & 0.003 & 0.002 & 0.001 & 0.001 & 0.007 & 0.005 \\
\hline Population & 0.003 & 0.002 & 0.001 & 0.007 & 0.001 & 0.005 \\
\hline Sum & 0.029 & 0.017 & 0.016 & 0.029 & 0.022 & 0.033 \\
\hline
\end{tabular}

\section{Conclusions and Recommendations}

There are many factors to insider for the installation of solar panels. If every factor is separately analyzed, then Weather may be thought the most important factor. As generating electricity with the solar panels, weather play important role and the area with the hottest weather may be selected. However, in this research various other factors are also considered and analyzed like, population, proximity of transmission lines, and security, etc. Analyzing all the factors with fuzzy AHP, Shergarh city is selected, where every criterion is at optimum point giving maximum results. Future work may be carried out on the same model by introducing the risk associated with the installation of solar panels in the selected city. In addition, economic analysis needed to be done for the installation process.

\section{Novelty Statement}

The paper deals the problem to select the optimized site location based on Fuzzy AHP technique for the solar farm by considering various factors in major cities of Khyber Pakhtunkhwa, Pakistan.

\section{Author's Contribution}

Rehman Akhtar: Supervision, data collection, analysis.

Khizar Azam: Supervision, data analysis, results.

Abdur Rehman Babar: Write up, data collection, data analysis.

Qazi Salman Khalid: Literature, data collection, results

Rashid Nawaz: Data collection and analysis.

Imran Ahmad: Data analysis, results.

\section{Conflict of interest}

The authors have declared no conflict of interest.

\section{References}

Aktas, A., and M. Kabak. 2019. A hybrid hesitant fuzzy decision-making approach for evaluating solar power plant location sites.Arab.J.Sci.Eng., 44(8): 7235-7247. https://doi.org/10.1007/ s13369-018-3604-5

Al-Garni, H.Z. and A. Awasthi. 2018. Solar PV power plants site selection: A review. Adv. Renew. Energ. Power Technol., pp. 57-75. https://doi.org/10.1016/B978-0-12-8129593.00002-2

Antipova, E., D. Boer, L.F. Cabeza, G. GuillénGosálbez and L.Jiménez. 2013. Multi-objective design of reverse osmosis plants integrated with solar Rankine cycles and thermal energy storage. Appl. Energy, 102: 1137-1147. https:// doi.org/10.1016/j.apenergy.2012.06.038

Arran-Carrion, J., et al. 2007. Environmental decision-support systems for evaluating the carrying capacity of land areas: Optimal site selection for grid-connected photovoltaic power plants. Renew. Sust. Energy Rev., 12: 2358-2380. https://doi.org/10.1016/j. rser.2007.06.011

Avila-Marin, A.L., J. Fernandez-Reche and F.M. Tellez. 2014. Evaluation of the potential of central receiver solar power plants: Configuration, optimization and trends. 
Appl. Energy, 112: 274-288. https://doi. org/10.1016/j.apenergy.2013.05.049

Azofra, D., E. Martínez, E. Jiménez, J. Blanco and J.C. Saenz-Díez. 2014. Comparison of the influence of biomass, solar-thermal and small hydraulic power on the Spanish electricity prices by means of artificial intelligence techniques. Appl. Energy, 121: 28-37. https:// doi.org/10.1016/j.apenergy.2014.01.064

Buckley, J.J., 1985. Fuzzy hierarchical analysis. Fuzzy Sets Syst., 17(1): 233-247. https://doi. org/10.1016/0165-0114(85)90090-9

Chakraborty, S., P.K. Sadhu and N. Pal. 2014. New location selection criterions for solar PV power plant. Int. J. Renew. Energy Res. (IJRER), 4(4): 1020-1030.

Chang, D.-Y., 1996. Applications of the extent analysis method on fuzzy AHP. Eur. J. Operat. Res., 95(3): 649-655. https://doi. org/10.1016/0377-2217(95)00300-2

Cheng, C.H., 1997. Evaluating naval tactical missile system by fuzzy AHP based on the grade value of membership function. Eur. J. Operat. Res., 96(2): 343-350. https://doi.org/10.1016/ S0377-2217(96)00026-4

Cheng, C.H., L.L. Yang and C.L. Hwang. 1999. Evaluating attack helicopter by ahp based on linguistic variable weight. Eur. J. Operat. Res., 116(2): 423- 435. https://doi.org/10.1016/ S0377-2217(98)00156-8

Chou, S-W. and Y-C. Chang. 2008. The implementation factors that influence the ERP (Enterprise Resource Planning) Benefits. Decis. Support Syst., 46(1): 149-157. https:// doi.org/10.1016/j.dss.2008.06.003

Dağdeviren, M. and I. Yüksel. 2009. Weapon selection using the AHP and TOPSIS methods under fuzzy environment. Expert. Syst. Appl., 36(4): 8143-8151. https://doi.org/10.1016/j. eswa.2008.10.016

Deng, H. and R.F. Boehm. 2011. An estimation of the performance limits and improvement of dry cooling on trough solar thermal plants. Appl. Energy, 88: 216-223. https://doi.org/10.1016/j. apenergy.2010.05.027

Desideri, U. and P.E. Campana. 2014. Analysis and comparison between a concentrating solar and a photovoltaic power plant. Appl. Energy, 113: 422-433. https://doi.org/10.1016/j. apenergy.2013.07.046

Dominguez, R., L. Baringo and A.J. Conejo.
2012. Optimal offering strategy for a concentrating solar power plant. Appl. Energy, 98: 316-325. https://doi.org/10.1016/j. apenergy.2012.03.043

Flueckiger, S.M. and S.V. Garimella. 2014. Latent heat augmentation of thermocline energy storage for concentrating solar power a system-level assessment. Appl. Energy, 116: 278-287. https://doi.org/10.1016/j. apenergy.2013.11.059

Flueckiger, S.M., B.D. Iverson, S.V. Garimella and J.E. Pacheco. 2014. System level simulation of a solar power tower plant with thermocline thermal energy storage. Appl. Energy, 113: 86-96. https://doi.org/10.1016/j. apenergy.2013.07.004

Guillot, S., A. Faik, A. Rakhmatullin, J. Lambert, E. Veron, P. Echegut, et al., 2012. Corrosion effects between molten salts and thermal storage material for concentrated solar power plants. Appl. Energy, 94: 174-181. https://doi. org/10.1016/j.apenergy.2011.12.057

Güngör, Z., G. Serhadlıŏglu and S.E. Kesen. 2009. A fuzzy AHP approach to personnel selection. Appl. Soft Comput., 9(2): 641-646. https://doi. org/10.1016/j.asoc.2008.09.003

Iverson, B.D., T.M. Conboy, J.J. Pasch and A.M. Kruizenga. 2013. Supercritical CO2 Brayton cycles for solar-thermal energy. Appl. Energy, 111: 957-970. https://doi.org/10.1016/j. apenergy.2013.06.020

Jafarian, M., M. Arjomandi and G.J. Nathan. 2014. The energetic performance of a novel hybrid solar thermal and chemical looping combustion plant. Appl. Energy, 132: 74-85. https://doi. org/10.1016/j.apenergy.2014.06.052

Kahraman, C. and I. Kaya. 2010. A fuzzy multicriteria methodology for selection among energy alternatives. Expert. Syst. Appl., 37(9): 6270-6281. https://doi.org/10.1016/j. eswa.2010.02.095

Kilic, H.S. and E. Cevikcan. 2011. Job selection based on fuzzy AHP: An investigation including the students of Istanbul technical university management faculty. Int. J. Bus. Manage. Stud., 3(1): 173-182.

Kilincci, O., and S.A. Onal. 2011. Fuzzy AHP approach for supplier selection in a washing machine company. Expert. Syst. Appl., 38(8): 9656-9664. https://doi.org/10.1016/j. eswa.2011.01.159 
Lee, A.H., H.Y. Kang and Y.J. Liou. 2017. A hybrid multiple-criteria decision-making approach for photovoltaic solar plant location selection. Sustainability, 9(2): 184. https://doi. org/10.3390/su9020184

Muñoz, J., J.M. Martínez-Val, R. Abbas and Abánades. 2012. A dry cooling with night cool storage to enhance solar power plants performance in extreme conditions areas. Appl. Energy, 92: 429-436. https://doi.org/10.1016/j. apenergy.2011.11.030

Noorollahi, E., D. Fadai, M. Akbarpour Shirazi and S.H. Ghodsipour. 2016. Land suitability analysis for solar farms exploitation using GIS and fuzzy analytic hierarchy process (FAHP) a case study of Iran. Energies, 9(8): 643. https:// doi.org/10.3390/en9080643

Önüt, S., S.S. Kara and E. Işık. 2009. Long term supplier selection using a combined fuzzy MCDM Approach: A case study for a telecommunication company. Expert. Syst. Appl., 36(2): 3887-3895. https://doi. org/10.1016/j.eswa.2008.02.045

Peng, Q., X. Yang, J. Ding, X. Wei and J. Yang. 2014. Design of new molten salt thermal energy storage material for solar thermal power plant. Appl. Energy, 112: 682-689. https://doi. org/10.1016/j.apenergy.2012.10.048

Peng, S., H. Hong, Y. Wang, Z. Wang and H. Jin. 2014. Off-design thermodynamic performances on typical days of a 330 MW solar aided coalfired power plant in China. Appl. Energy. $5^{\text {th }}$ Int. Conf.Appl.Energy(ICAE),JUL 01-04.https:// doi.org/10.1016/j.apenergy.2014.01.096

Petkovic, J., Z. Sevarac, M.L. Jaksic and S. Marinkovic. 2012. Application of fuzzy AHP method for choosing a technology within service company. Tech. Technol. Educ. Manag., 7(1): 332-341.

Rovira, A., M.J. Montes, M. Valdes and J.M. Martínez-Val. 2011. Energy management in solar thermal power plants with double thermal storage system and subdivided solar field. Appl. Energy, 88: 4055-4066. https://doi. org/10.1016/j.apenergy.2011.04.036

Ruoning,X. and Z.Xiaoyan.1992. Extensions of the analytic hierarchy process in fuzzy environment. Fuzzy Sets Syst., 52(3): 251-257. https://doi. org/10.1016/0165-0114(92)90236-W

Sanz-Bermejo, J., J. Muñoz-Antón, J. GonzalezAguilar and M. Romero. 2014. Optimal integration of a solid-oxide electrolyser cell into a direct steam generation solar power plant for zero-emission hydrogen production. Appl. Energy, 131: 238-247. https://doi. org/10.1016/j.apenergy.2014.06.028

Saaty,T.L., 2008. Decision making with the analytic hierarchy process. Int. J. Serv. Sci., 1(1): 83-98.

Uyan, M., 2013. GIS-based solar farms site selection using analytic hierarchy process (AHP) in Karapinar region, Konya/Turkey. Renew. Sust. Energ. Rev., 28: 11-17. https:// doi.org/10.1016/j.rser.2013.07.042

Van Haaren, R. and V. Fthenakis. 2011. GIS-based wind farm site selection using spatial multicriteria analysis (SMCA): Evaluating the case for New York State. Renew. Sust. Energy Rev., pp. 3332-3340. https://doi.org/10.1016/j. rser.2011.04.010

Van Laarhoven, P.J.M. and W. Pedrycz. 1983. A fuzzy extension of Saaty's priority Theory. Fuzzy Sets and Systems, 11(1-3): 199-227. https:// doi.org/10.1016/S0165-0114(83)80081-5

Wu, S-Y., L. Xiao, Y. Cao and Y-R. Li. 2010. A parabolic dish/AMTEC solar thermal power system and its performance evaluation. Appl. Energy, 87: 452-462. https://doi.org/10.1016/j. apenergy.2009.08.041

Wu, Y., S. Geng, H., Zhang and M. Gao. 2014. Decision framework of solar thermal power plant site selection based on linguistic Choquet operator. Appl. Energy, 136:303-311.

Xiao, J., Z. Yao, J. Qu and J. Sun. 2013. Research on an optimal site selection model for desert photovoltaic power plants based on analytic hierarchy process and geographic information system. J. Renew. Sustain. Energy, 2013: 5. https://doi.org/10.1063/1.4801451

Yang, Z. and S.V. Garimella. 2013. Cyclic operation of molten-salt thermal energy storage in thermoclines for solar power plants. Appl. Energy, 103: 256-265. https://doi. org/10.1016/j.apenergy.2012.09.043

Yun-na, W., Y. Yi-sheng, F. Tian-tian, K. Lina, L. Wei and F. Luo-jie. 2013. Macro-site selection of wind/solar hybrid power station based on ideal matter-element model. Electr. Power Energy Syst., 50: 76-84. https://doi. org/10.1016/j.ijepes.2013.02.024

Zadeh, L.A., 1965. Fuzzy sets. Inf. Contr., 8(3): 199-249. https://doi.org/10.1016/S00199958(65)90241-X 